\title{
Las personas jurídicas consumidoras. El caso de las cooperativas de consumidores y usuarios
}

\author{
Eugenia Fernández Fernández \\ Universidad de Cantabria
}

Recibido: 16-04-2018

Aceptado: 18-05-2018

\begin{abstract}
Sumario: 1. Introducción. 2. El concepto de consumidor en nuestro ordenamiento jurídico 2.1. La versión inicial de la Ley general para la defensa de los consumidores y usuarios de 2007. La superación del concepto de destinatario final. 2.2. La revisión del concepto operada en 2014. Especial referencia al consumidor persona jurídica. 3. El caso de las cooperativas de consumidores. ¿consumidor o empresario? 3.1. La cooperativa como proveedora de bienes o servicios. 3.2. La cooperativa como adquirente de bienes o servicios de otros empresarios. 4. Bibliografía
\end{abstract}

Resumen: Las normas en materia de protección a los consumidores han experimentado una notable expansión desde los años setenta. Primigeniamente concebido como un conjunto de normas aplicables únicamente a las personas físicas, nuestro ordenamiento jurídico presenta una particularidad frente a otros de nuestro entorno y es la extensión del concepto de consumidor a las personas jurídicas. En el presente supuesto se pretende no tanto analizar el concepto de consumidor persona jurídica sino su aplicabilidad a un concreto tipo de persona jurídica como es la sociedad cooperativa y, particularmente, a la cooperativa de consumidores y usuarios con el propósito de arrojar luz sobre una cuestión que ha dado lugar a pronunciamientos judiciales dispares.

Palabras clave: protección de consumidores, concepto de consumidor, persona física, persona jurídica, cooperativa de consumo

Abstract: Consumer protection laws have experimented a huge expansion from seventies. Initially designed to be applied only to natural person, our system has a singularity: the inclusion in the law of the legal persons as consumer. In this essay we'll try to analyse not only the concept of legal person as consumer but the applicability of consumer protection law to an specific type of legal person that is the cooperative and specifically the consumer cooperatives with the aim to clarify a problematic topic that has motivated conflicts in the practice

Keywords: consumer legal protection, notion of consumer, natural person, legal person, consumer cooperative 


\section{Introducción}

Las normas en materia de protección jurídica de los consumidores han sufrido desde su tímida aparición en la década de los setenta del siglo pasado un extraordinario desarrollo en los últimos años. Inicialmente vinculadas a una finalidad tuitiva que aún sigue presente y constituye su $A D N$, se han convertido, sin embargo, en normas que trascienden su inicial vocación y vertebran el correcto funcionamiento del mercado reequilibrando las posiciones jurídicas de los intervinientes en aquel. Primigeniamente concebido como un conjunto de normas aplicables únicamente a las personas físicas, nuestro ordenamiento jurídico presenta una particularidad frente a otros de nuestro entorno y es la extensión del concepto de consumidor a las personas jurídicas. En el presente supuesto se pretende no tanto analizar el concepto de consumidor persona jurídica sino su aplicabilidad a un concreto tipo de persona jurídica como es la sociedad cooperativa y, particularmente, a la cooperativa de consumidores y usuarios con el propósito de arrojar luz sobre una cuestión que ha dado lugar a pronunciamientos judiciales dispares.

\section{El concepto de consumidor en nuestro ordenamiento jurídico}

Todas las normas en materia de protección al consumidor sitúan a éste como sujeto destinatario de las especiales medidas de protección que articulan. Central resulta, por tanto, la correcta definición de lo que haya de entenderse por consumidor ${ }^{1}$. Conviene aclarar en este

1 Ha de hacerse la advertencia previa de que, en brillantes palabras de VICENT CHULIÁ, F.: Introducción al Derecho Mercantil, Valencia, 2008, p. 59, el concepto de consumidor es «proteico y caleidoscópico» resultando de gran dificultad técnica la correcta delimitación del mismo. Aun cuando la LGDCU contiene un concepto legal de pretendida aplicación general lo cierto es que son muy numerosas las normas sectoriales que acuñan conceptos propios de consumidor no siempre coincidentes y a menudo contradictorios con la formulación de aquélla. A esta circunstancia se une, además, la existencia de normas autonómicas en materia de protección al consumidor que formulan sus propios conceptos de consumidor. Tales dificultades definitorias han sido apuntadas por ReCALDE CASTELLS, A.: «El derecho de consumo como derecho especial», en Tomillo URBINA, J (dir.): El futuro de la protección jurídica de los consumidores, Navarra, 2008, p. 537-568, en concreto p. 548, como uno de los mayores impedimentos a la hora de delimitar el derecho de consumo como un derecho especial frente al derecho común. El autor realiza un interesante análisis, que sin embargo no compartimos, sobre la justificación de las medidas de protección al consumidor como vía para corregir la desigualdad 
punto que la condición de consumidor de un sujeto no es una característica inmutable y abstracta atribuible en atención a determinados rasgos sino que, antes al contrario, se trata de una condición esencialmente mutable que depende del lugar que ese sujeto ocupa en una determinada relación contractual. Se trata de una condición asociada al rol concreto que el sujeto ocupa en cada relación contractual de forma que un mismo sujeto puede variar su calificación en cada relación en la que tome parte? .

estructural que padecen los consumidores en sus relaciones contractuales. En su opinión la incidencia de las normas de protección a los consumidores en algunos fundamentos básicos del derecho privado tradicional no sólo supone una ruptura del clásico dogma de la neutralidad ideológica de aquel sino que no resulta ni necesaria ni justificada en tanto que existen otros instrumentos, como el derecho antitrust, a través de los cuales se puede conseguir idéntica labor de reequilibrio de situaciones estructurales de debilidad sin afectar a los postulados clásicos del derecho privado. El autor niega la autonomía del derecho de consumo no sólo por las dificultades que entraña la determinación de su ámbito subjetivo de aplicación sino también porque resulta difícil apreciar la razón sustantiva del derecho especial del consumo al considerar que «la identificación de un principio de tutela del consumidor no sería suficiente para disgregar una rama respecto del resto del ordenamiento». En la medida en que la debilidad estructural que suele invocarse para justificar la intervención normativa no concurre de forma exclusiva en las relaciones en que intervienen consumidores no puede utilizarse esa «pretendida» debilidad como argumento axiológico que justifique las medidas de intervención. A juicio del autor la generalización de las normas intervencionistas en aras de la protección del consumidor podría entrañar costes desmesurados y dar lugar a la aparición de grupos económicos organizados capaces de orientar el camino del legislador hacia las posiciones que resultan más favorables a sus intereses.

2 Miranda SerRano, L.M.: "La protección de los consumidores en la contratación: aspectos generales», en Miranda Serrano, L.M./Vela Torres, P. J./Príes Picardo, A.: La contratación mercantil. Disposiciones generales. Protección de los consumidores, Madrid, 2006, pp. 179 -221, p. 195 y 196 afirma que la condición de consumidor responde a un rol social en tanto que nadie es consumidor sino que se comporta o actúa en determinados ámbitos como tal. Lo que ha ocasionado, según el autor, que cierta doctrina prefiera aludir al acto de consumo como elemento delimitador de la aplicación del derecho de consumo. En el mismo sentido se manifiesta Calais Auloy, J.: Droit de la consommation, 9. ${ }^{a}$ ed, París, 2015, p. 20 afirma que los consumidores no constituyen una clase especial diferente a los ciudadanos sino que tal calificación se derivará del tipo de acto que, en cada caso, esté llevando a cabo el sujeto 


\subsection{La versión inicial de la Ley general para la defensa de los consumidores y usuarios de 2007. La superación del concepto de destinatario final}

La LGDCU aprobada en $2007^{3}$ enuncia un concepto de consumidor esencialmente idéntico en cuanto a su contenido 4 pero de diferente formulación al concepto que postulaba la LGDCU de $1984^{5}$. Así

3 La nueva LGDCU ha sido aprobada por el Real Decreto Legislativo 1/2007, de 16 de noviembre, por el que se aprueba el Texto Refundido de la Ley General para la Defensa de los Consumidores y Usuarios y otras normas complementarias ( $B O E$ de 30 de noviembre de 2007, corrección de errores en BOE de 13 de febrero de 2008).

4 Así lo entiende Bercovitz Rodríguez-Cano, R.: "Comentario al artículo 3», en BerCovitz Rodríguez-CANo, R. (coord.): Comentario al texto refundido de la ley general para la defensa de los consumidores y otras normas complementarias, Cizur Menor, 2008, p. 90 para quien el colectivo al que se sigue refiriendo la protección es el de personas que actúan para la satisfacción de necesidades de índole personal, familiar o doméstica. Si bien el supuesto de hecho al que la definición se refiere no ha variado sustancialmente sí lo ha hecho la formulación de la norma circunstancia que puede plantear la duda de si el Gobierno se ha extralimitado en el cumplimiento del mandato contenido en la norma de habilitación (Disp. Fin. 5. ${ }^{a}$ de la Ley 44/2006, de 29 de diciembre, de mejora de la protección de los consumidores y usuarios) incurriendo en un supuesto de ultra vires. La habilitación legislativa ordenaba al gobierno refundir en un mismo texto la antigua Ley General para la Defensa de los Consumidores y Usuarios de 1984 y las normas sectoriales fruto de la trasposición de normas comunitarias «regularizando, aclarando y armonizando los textos legales que tengan que ser refundidos» con lo cual habrá de determinarse hasta qué punto la variación siquiera nominal del concepto de consumidor está amparada o no por el mandato legislativo. En este sentido parece que, dado que el cambio no implica la extensión del concepto sino una reformulación del mismo para situarlo en la línea del concepto comunitario tal cambio no habría mayores problemas para salvar el riesgo de extralimitación legislativa apuntado. Convenimos en este punto con lo afirmado por Bercovitz Rodríguez-CANo, R.: ob. cit. p. 90.

5 El concepto de consumidor que esta norma contenía se definía doblemente desde un punto de vista positivo y negativo. Desde un punto de vista positivo la norma atribuía la consideración de consumidores a «las personas físicas o jurídicas que adquieren, utilizan o disfrutan como destinatarios finales, bienes muebles o inmuebles, productos, servicios, actividades o funciones, cualquiera que sea la naturaleza pública o privada, individual o colectiva de quienes los producen, facilitan, suministran o expiden». Desde el punto de vista negativo «No tendrán la consideración de consumidores o usuarios quienes sin constituirse en destinatarios finales, adquieran, almacenen, utilicen o consuman bienes o servicios, con el fin de integrarlos en procesos de producción, transformación, comercialización o prestación a terceros». MiRANDA SERRANO, L.M.: ob. cit. p. 200 afirma que, a la vista de las carencias técnicas del artículo 1 LGDCU, se impone la necesidad de corregir por vía interpretativa la desafortunada redacción del legislador. A tal efecto ha de interpretarse que el verdadero núcleo de la definición se encuentra en el artículo 1.2 mientras que el artículo 1.3 no hace sino completarlo (con poco acierto) definiendo en negativo los criterios con arreglo a los cuales un sujeto no es destinatario final del bien. Esa formulación negativa es la que a juicio del autor (que compartimos) introduce un elemento de distorsión que ha dado lugar a interpretaciones incorrectas del sentido de la norma. De hecho propone una reinterpretación del ar- 
el artículo 3 establece lo siguiente: «A efectos de esta norma (...) son consumidores o usuarios ${ }^{6}$ las personas físicas o jurídicas que actúan en un ámbito ajeno a una actividad empresarial o profesional». Esta diferente formulación ha de valorarse positivamente por un doble motivo. En primer lugar porque se acomoda plenamente a la definición históricamente utilizada en el derecho comunitario ${ }^{8}$ y en segundo término porque resulta mucho más clara que la anterior. La atribución de la condición de consumidor ya no depende de la actuación en calidad de destinatario final del bien, un concepto de perfiles un tanto difusos cuya interpretación se había manifestado harto problemática durante los años de vigencia de la ley anterior, sino de que la adquisición se realice al margen de cualquier actividad empresarial o profesional, circunstancia esta de mucha más fácil y objetiva apreciación. La nueva formulación permite superar algunas interpretaciones erróneas de la expresión destinatario final, únicamente centradas en un aspecto puramente locativo según las cuales la mera ausencia de transmisión o reventa del bien era suficiente para calificar al adquirente como consumidor y, contrario sensu, cualquier transmisión de que fuera objeto el bien excluía a su adquirente de la consideración como consumidor ${ }^{9}$.

tículo 1.3 LGDCU que prescinda de algunas de sus expresiones para hallar el verdadero sentido del mismo

6 Tomillo UrbinA, J.: ob. cit. p. 43-44 critica la ligereza con que se emplea el término de usuario como sinónimo de consumidor cuando en realidad los vocablos se refieren a dos clases de relaciones jurídicas distintas. El consumidor es quien interviene como parte en una relación jurídica de consumo mientras que el usuario es quien accede a la utilización del producto «merced a una relación jurídica de consentimiento o tolerancia entablada no frente al empresario o profesional sino con el consumidor o adquirente». Aun cuando la cuestión carece de trascendencia jurídica en tanto que a ambos les resulta aplicable el mismo régimen jurídico, razones de corrección técnica reclamarían un uso apropiado de uno y otro término. En el mismo sentido se pronuncia BERCOVITZ RODRíGUEZ-CANO, R.: ob. cit. p. 96 quien afirma, no obstante, que la denominación de usuario no sirve para nada salvo para confundir haciendo pensar que el consumidor se refiere a los bienes y el usuario a los servicios, distinción que, afirma, carece de sentido alguno.

7 La expresión "empresarial o profesional» constituye una duplicidad inútil puesto que, por definición, todo profesional es empresario. Así lo pone de relieve BERCovitz RoDRÍGUEZ-CANO, R. ob. cit., p. 91 para quien hubiese bastado con referirse la expresión empresario, más amplia y que comprende también a los profesionales.

8 También contenido en la Directiva 2011/83, de 25 de octubre, del Parlamento Europeo y del Consejo, sobre derechos de los consumidores que en su art. 2.1 define al consumidor como «toda persona física que, en los contratos regulados por la presente directiva, actúe con un propósito ajeno a su actividad comercial, empresa, oficio o profesión».

9 Bercovitz Rodríguez-Cano, R.: ob. cit. p. 87 deja claro que quedan excluidos de la consideración como actividad empresarial la producción, transformación, comercialización o prestación a terceros realizadas en favor de amigos y familiares. 
Parece claro que en ningún caso puede ser este el único criterio de discernimiento puesto que conduciría a calificar erróneamente tanto los consumos empresariales como las transmisiones en el ámbito familiar o doméstico. En el primer caso y aun cuando las mercancías adquiridas no sean objeto de reventa es claro que se emplean en la realización de una actividad empresarial y que quien las adquiere no necesita una protección especial ${ }^{10}$. En el segundo, aun cuando se pueda realizar una transmisión lo cierto es que la misma se desenvuelve en el ámbito puramente doméstico o familiar y siempre al margen de cualquier actividad empresarial o profesional ${ }^{11}$. Del mismo modo, la adquisición de bienes que con posterioridad van a ser sometidos a algún tipo de transformación o manufactura también quedará protegida por la norma siempre y cuando tal actividad de manipulación no se realice de manera empresarial o profesional12.

\subsection{La revisión del concepto operada en 2014. Especial referencia al consumidor persona jurídica}

La Ley 3/2014, de 27 de marzo, por la que se modifica el Texto Refundido de la Ley general para la defensa de los consumidores y usuarios y otras normas complementarias aprobada por el Real Decreto Legislativo 1/2007, de 16 de noviembre (BOE n. ${ }^{\circ}$ 76, de 28 de marzo) se

10 Bercovitz Rodriguez-CANo, R.: ob. cit. p. 88 afirma textualmente que «no basta pues que quien adquiera bienes o servicios no proceda a su reventa o comercialización ulterior. De ahi que el destino final empresarial o profesional de un bien o servicio no transforme a su adquirente en un consumidor». El mismo autor cita, como ejemplo de un incorrecto entendimiento de la expresión «destinatario final» la SAP de Madrid, sección 10a, de 26 de abril de 2004 (AC 2004\1201) que considera consumidor al adquirente de un equipo informático para traducciones de carácter profesional por no tener como destino su reventa.

11 Tomillo URBinA, J. L., ob. cit. p. 43 sostiene idéntica opinión referida al concepto de consumidor contenido en la ley cántabra de protección de los consumidores y usuarios que, con algunas diferencias que no inciden en este punto, resulta similar al que ha adoptado el Real Decreto Legislativo 1/2007, de 16 de noviembre, por el que se aprueba el Texto Refundido de la Ley General para la Defensa de los Consumidores y Usuarios y otras normas complementarias.

12 Este sería el supuesto ya citado con anterioridad de adquisición de semillas para cultivar un huerto familiar o de lana para confeccionar prendas de abrigo. Aun cuando en puridad tales productos se ven sometidos a un proceso de transformación o manufactura, lo cierto es que, por desenvolverse tal manipulación en el ámbito puramente doméstico, no puede despojarse al sujeto que los adquiere de la protección reforzada que le otorga la consideración de consumidor. La teleología de las normas de protección al consumidor en ningún caso ampararía semejante conclusión. 
aprobó con el objetivo de trasponer a nuestro ordenamiento interno la Directiva 2011/83/UE del Parlamento Europeo y del Consejo, de 25 de octubre de 2011, sobre los derechos de los consumidores, por la que se modifican la Directiva 93/13/CEE del Consejo y la Directiva 1999/44/ CE del Parlamento Europeo y del Consejo y se derogan la Directiva 85/577/CEE del Consejo y la Directiva 97/7/CE del Parlamento Europeo y del Consejo. Esta norma ha tenido como principal efecto, en lo que ahora nos interesa, la modificación del artículo 3 LGDCU referido al concepto de consumidor para adaptarlo (copiarlo literalmente para ser más exactos) al contenido de la Directiva. En relación con las personas físicas la modificación apenas tiene consecuencias prácticas puesto que la nueva definición es sustancialmente idéntica a la anterior. En ambos casos lo relevante es que la adquisición del bien o del servicio se materialice en un ámbito ajeno a cualquier actividad empresarial o profesional. Solamente algunos pequeños matices sin mayor trascendencia diferencian ambos conceptos. En el concepto de 2007 se hacía referencia a la actuación en un «ámbito ajeno» mientras que en la nueva definición se hace referencia a la actuación con «propósito ajeno» sin que ello suponga que el enfoque objetivo se reemplaza por otro de carácter subjetivo; la referencia a la "actividad empresarial o profesional» del texto originario se sustituye por la alusión a la «actividad comercial, empresa, oficio o profesión» sin que de nuevo el cambio suponga alteración del ámbito al que se refiere, antes al contrario, se introducen en el nuevo texto reiteraciones innecesarias en relación con la actividad comercial, el oficio o la profesión en tanto que todos estos conceptos resultan comprendidos en la expresión más genérica de actividad empresarial que puede ir referida a cualquier sector, incluido el comercial y el profesional. Se trata en definitiva de pequeños matices que nada añaden con respecto a la formulación anterior y que deberían ser corregidos por el legislador ${ }^{13}$.

13 Bercovitz Rodríguez-Cano, R.: «Comentario al artículo 3», en Bercovitz RodríguezCANo (dir.): Comentarios al Texto refundido de la Ley general para la defensa de los consumidores y usuarios y otras normas complementarias, 2. ${ }^{a}$ ed., Cizur Menor, 2015, p. 60. En el mismo sentido MARín LOPEZ, M. J.: «El nuevo concepto de consumidor y empresario tras la Ley 3/2014, de reforma del TRLGDCU», Revista CESCO de Derecho de consumo, n. ${ }^{\circ}$, 2014, pp. 9-16 y en particular en la p. 10 y 11 se sitúa en la misma línea aunque llama la atención sobre otra modificación que la Ley 3/2014 opera en el artículo 3 y que, pese a la apariencia inicial no resulta tampoco ser de gran calado. Se refiere al autor al hecho de que en el nuevo texto se haga referencia a la actuación con propósito ajeno a su actividad comercial, empresarial, oficio o profesión mientras que la redacción anterior se refería a la actuación ajena a una actividad empresarial o profesional. A la vista del cambio podría pensarse que el nuevo texto está dando cabida en el concepto 
La normativa española de protección a los consumidores presenta una particularidad que debe ser analizada en este punto. Y es que, a diferencia de las normas comunitarias, la calificación de consumidor se ha venido predicando históricamente no sólo a las personas físicas sino también a las jurídicas ${ }^{14}$. Esta arraigada tendencia15, tradicionalmente amparada en el principio de armonización mínima de las normas de protección a los consumidores, genera, sin embargo, ciertas asimetrías de regulación entre la normativa comunitaria y la nacional lo que

de consumidor a aquellos empresarios que adquieren bienes o contratan servicios que pertenecen al ámbito de su especialidad sino que guardan con ésta una relación instrumental o mediata (Ej.: un abogado que contrata una alarma para su despacho). De ser así estaríamos ante un cambio de gran trascendencia en tanto que se incorporaría al derecho de consumo a los empresarios no especialistas. Sin embargo, una interpretación sistemática de la norma en relación con la exposición de motivos en la que se alude a que el empleo de los bienes en una actividad empresarial no puede ser ni directo ni indirecto y con el propio artículo 3.2 donde se sigue haciendo referencia a la actuación al margen de una actividad empresarial o profesional nos llevan a concluir que el cambio no tiene la envergadura que pudiera parecer inicialmente y no es más que una variación, probablemente inconsciente, en la formulación del precepto que carece de consecuencias prácticas.

14 Las normas comunitarias así como la jurisprudencia del TJCE siguen una clara línea en cuya virtud las personas jurídicas no gozan de la consideración de consumidores. En este sentido se ha pronunciado el TJCE en sentencia de 22 de noviembre de 2001 [Cape Snc contra Idealservice Srl (C-541/99) y Idealservice MN RE Sas contra OMAI Srl (C-542/99)]. Idealservice procedió a la instalación de sendas máquinas expendedoras de bebidas en los establecimientos mercantiles de las demandantes (Cape y OMAI) destinadas exclusivamente a dar servicio a los trabajadores de éstas. En la ejecución del contrato se generó una controversia que motivó la demanda de Cape y OMI en la que alegaban la nulidad de determinadas cláusulas contractuales amparándose en la protección que les dispensaba la directiva sobre cláusulas abusivas en la contratación consumidores. La defensa de Idealservice niega el carácter de consumidor de las demandantes y, por ende, la aplicabilidad de la directiva. En la sentencia el tribunal se pregunta si una persona jurídica y más concretamente una sociedad puede considerarse consumidor concluyendo de forma tajante que «El concepto de «consumidor», tal como se halla definido en el artículo 2, letra b), de la Directiva 93/13/CEE del Consejo, de 5 de abril de 1993, sobre las cláusulas abusivas en los contratos celebrados con consumidores, debe interpretarse en el sentido de que se refiere exclusivamente a las personas físicas.»

15 Esta tendencia no ha sido corregida tampoco con la aprobación de la Ley General para la Defensa de los Consumidores y Usuarios de 2007 probablemente por el tenor del mandato que recibió el ejecutivo que únicamente se encontraba facultado a refundir, armonizar y coordinar, nunca a introducir modificaciones de calado como habría sido la alteración del tradicional concepto de consumidor. Como una de las normas que excepcionalmente restringe la condición de consumidor a las personas físicas cabe citar la Ley 16/2011, de 24 de junio, de Contratos de crédito al consumo que en su artículo 2.1 afirma que «a efectos de esta Ley, se entenderá por consumidor la persona física que, en las relaciones contractuales reguladas por esta Ley, actúa con fines que están al margen de su actividad comercial o profesional». 
ha sido objeto de numerosas y fundadas críticas que, con buen criterio, evidencian la necesidad de proceder a una reforma de nuestro derecho en este punto ${ }^{16}$.

Aun cuando podría admitirse que determinadas colectividades (personas jurídicas pero no sólo personas jurídicas) que no realizan labores de producción, transformación y comercialización en el mercado puedan encontrarse en una posición equiparable a la de una persona física y por tanto requieran similares medidas de protección, no puede, sin embargo, generalizarse tal afirmación. La referencia genérica a las personas jurídicas resulta muy criticable. Utilizando una expresión coloquial pero muy ilustrativa, ni son todas las que están ni están todas las que son. En primer lugar porque no todas las personas jurídicas podrán considerarse consumidoras. Habría de tratarse de una persona jurídica que actúe al margen de cualquier actividad empresarial o profesional ${ }^{17}$,

16 Bercovitz Rodríguez-CANo, A.: "El concepto de consumidor», en AZPARREN LUCAS; A. (dir): Hacia un código del consumidor, 2006, pp. 19-37, en concreto, pp. 32 a 34. Según el autor, lo realmente problemático es que la noción de consumidor de la LGDCU (que incluye a las personas jurídicas) no se puede aplicar en las leyes que trasponen Directivas comunitarias donde la noción de consumidor se refiere exclusivamente a las personas físicas. Y ello porque el principio de armonización mínima permite a los Estados ampliar los derechos reconocidos por las normas comunitarias pero en ningún caso sustenta la ampliación del ámbito de aplicación de las mismas que es lo que ocurre cuando se extiende la noción de consumidor a las personas jurídicas. El autor advierte, asimismo, que este principio de armonización mínima no debe aplicarse a las medidas de protección de los consumidores que se adopten «en el marco de la realización del mercado interior» (artículo 153.3.a del Tratado de la Unión Europea), circunstancia que claramente concurre en la regulación de los efectos del contrato de compraventa. Por todo ello, el autor se muestra partidario de terminar con la inveterada tradición española de extender la noción de consumidor a las personas jurídicas.

17 Bercovitz Rodríguez-CANo, A.: ob. cit. p. 41 no considera consumidoras a las cooperativas de consumidores por entender que realizan una actividad de comercialización dentro del mercado en tanto que no sólo proveen de bienes a sus asociados sino a terceros ajenos y siempre mediante contraprestación económica. Según este autor, la persona jurídica consumidora deberá carecer de ánimo de lucro y transmitir a título gratuito los bienes o servicios adquiridos, de una manera similar a lo que acontece en las cesiones dentro del ámbito familiar o doméstico lo que, según él, ocurre con las fundaciones o asociaciones o con las comunidades de propietarios, "que adquieren bienes o servicios para que sean utilizados por los miembros de la entidad o por personas a ellas vinculadas pero siempre que la cesión individualizada de los bienes o servicios para su utilización se haga a título gratuito». Esta interpretación chocaba con la propia realidad puesto que en buena parte de los casos la prestación de servicios por parte de asociaciones, fundaciones y comunidades de bienes a sus miembros se realiza de forma onerosa. Ha de hacerse notar que con la nueva redacción de la LGDCU de 2007, que únicamente exige la actuación en un ámbito ajeno a cualquier actividad empresarial o profesional, podría prescindirse de la consideración tanto del ánimo de lucro como de la gratuidad de los bienes o servicios superándose la in- 
circunstancia esta que permitiría excluir, por ejemplo, a las sociedades mercantiles, sujetos paradigmáticos de la actividad empresarial. En segundo lugar porque existen otras realidades sin personificación jurídica que, por estar en idéntica posición al consumidor, debieran tener su misma consideración y, sin embargo, no tendrían cabida en la norma. Tal es el caso de las comunidades de bienes a las que una interpretación estricta de la LGDCU situaría fuera del ámbito de la ley por carecer de personalidad jurídica aun cuando no parece que existan inconvenientes para considerarlas consumidores cuando su función no excede de la pura gestión y administración de bienes comunes titularidad de los comuneros ${ }^{18}$.

El artículo 3 LGDCU que en su redacción originaria incluía en la misma proposición a las personas físicas y a las jurídicas ha quedado ahora dividido en dos apartados dedicados a cada una de ellas. El apartado 3.2 LGDCU declara que "Son también consumidores a efectos de esta norma las personas jurídicas y las entidades sin personalidad jurídica que actúen sin ánimo de lucro en un ámbito ajeno a una actividad comercial o empresarial». En este caso, las diferencias introducidas por la Ley 3/2014 sí son de calado y recogen algunas de las críticas que la doctrina había formulado con respecto a la ya inveterada tradición es-

terpretación un tanto forzada que el autor se ve obligado a articular para justificar la exclusión de las cooperativas al tiempo que la inclusión de asociaciones, fundaciones y comunidades de bienes. Con la redacción de 2007 todas ellas quedarían cubiertas siempre que no realicen una actividad de carácter empresarial o profesional y ello aun cuando puedan prestar servicios a sus miembros mediante contraprestación económica. En este sentido se manifiesta Bercovitz Rodríguez-Cano, R.: ob. cit. p. 94. El tratamiento jurisprudencial de esta cuestión ha sido profundamente equivocado y existen numerosas sentencias en las que se aplican normas de protección al consumidor a relaciones jurídicas trabadas entre dos sociedades mercantiles, ambas en el pleno ejercicio de su actividad empresarial. Así resultan llamativas, por descabelladas, la STS de 13 de noviembre de 1995 (RJ 1995\8601) que resuelve un conflicto entre una sociedad anónima dedicada a la comercialización de productos deportivos y turísticos con otra sociedad, también anónima, ambas partes en un contrato de leasing, y en la que el tribunal anula por abusivas y contrarias al artículo 10 de la por entonces vigente Ley general para la defensa de los consumidores y usuarios de 1984 determinadas cláusulas del contrato; la SAP de Valencia de 26 de enero de 1999 (AC 19991100), en la que el tribunal anula por abusivas a la luz de la LGDCU de 1984 varias cláusulas de un contrato de concesión entre dos sociedades mercantiles.

18 Así lo entiende Bercovitz, R.: ob. cit. p. 94 que, sin embargo, excluye a aquellas comunidades que no se dediquen a la gestión y administración de un bien común sino a la realización de actividades empresariales. La jurisprudencia se ha mostrado con mucha frecuencia partidaria de una interpretación inclusiva de la LGDCU que permitiera extender la aplicación de sus normas a las comunidades de propietarios en sus relaciones con las empresas proveedoras de servicios de mantenimiento, ascensores, etc. 
pañola de considerar a las personas físicas como consumidoras ${ }^{19}$. Y es que la forma en que se hacía ese reconocimiento pecaba no tanto por exceso como por defecto al no incluir ningún criterio de ponderación. Particularmente grave era la exclusión de los entes sin personalidad jurídica como las comunidades de bienes que, por carecer de la personalidad quedaban al margen del derecho de consumo siendo uno de los colectivos más necesitados de protección (en relación con la contratación de servicios de ascensor, mantenimiento, seguros, etc.). Con la expresa referencia a las entidades sin personalidad jurídica el problema queda definitivamente resuelto y a salvo de pronunciamientos judiciales contradictorios.

La inclusión de las personas jurídicas, como decimos, completada con las entidades sin personalidad jurídica, se condiciona al cumplimiento de dos requisitos que el propio artículo recoge: la actuación al margen de cualquier actividad empresarial o profesional y la ausencia de ánimo de lucro. El primero de los requisitos ya se encontraba en el texto anterior y resulta, además, plenamente lógico en tanto que sigue la línea marcada para las personas físicas. De manera que la inclusión en el concepto de consumidor queda reservada únicamente a aquellas personas jurídicas o entidades sin personalidad que actúen al margen de una actividad empresarial o profesional. Lo que supone excluir a todas las sociedades mercantiles y aquellas sociedades civiles cuyo objeto sea el desempeño de una actividad empresarial20. En cuanto a las fundaciones habría que distinguir los casos en los que estas realizan una actividad empresarial, que excluiría su condición de consumidor, de aquellos otros en los que no se produzca una actividad de esa naturaleza ${ }^{21}$. La actuación al margen de una actividad empresarial o profesional por parte de las asociaciones y, por ende, su

19 Bercovitz Rodríguez-Cano, R.: ob. cit. p. 61 afirma que ello no supone problemas de encaje en la Directiva 2011/83/CE pues aunque la misma se plantea como de armonización máxima, se trataría de una cuestión que quedaría fuera de su ámbito de aplicación (únicamente referido a las personas físicas) y del alcance armonizador con lo que los Estados conservarían plena libertad de regulación. Así lo indica el párrafo decimotercero de la exposición de motivos de la Directiva.

20 CÁmARA LAPUENTE, S.: «El concepto legal de consumidor en el derecho privado europeo y en el derecho español: aspectos controvertidos o no resueltos», Cuadernos de derecho transnacional, marzo 2011, vol. 3, n. ${ }^{\circ}$ 1, pp. 84-117 afirma en la p. 100 que las fundaciones y las cooperativas no podrían ser consideradas como consumidores en tanto que revisten rasgos de operadores económicos o participantes en el mercado (aunque el artículo 23.1.2 LGDCU equipara las cooperativas de consumidores a las asociaciones de consumidores). Quedarían incluidas únicamente las asociaciones siempre que no lo fuesen de empresarios o de profesionales.

21 Marín López, M. J.: ob. cit. p. 14. 
hipotética consideración como consumidoras, viene determinada por quiénes sean los destinatarios de los bienes o servicios que contratan de forma que en los casos en que esos servicios revierten en el ámbito interno de la asociación cabría su consideración como consumidoras $^{22}$.

La novedad del artículo 3 reside en la exigencia de que las personas jurídicas no tengan ánimo de lucro ni directa ni indirectamente, exigencia que no se contemplaba hasta el momento aunque había sido referida por la doctrina. Podría considerarse como una exigencia prescindible en tanto que no siendo un requisito necesario para la calificación de un sujeto como empresario ningún sentido tiene que lo sea para la calificación inversa y porque, acreditada la circunstancia de que el sujeto no está realizando una actividad empresarial, no hay razón para que la concurrencia de ánimo de lucro prive de protección a determinados sujetos en el marco de auténticas relaciones de consumo 23 .

Ninguna duda suscita la inclusión en el concepto de consumidor de las comunidades de bienes que no desempeñen una actividad empresarial. De hecho es muy probable que la inclusión de estas en el concepto de consumidor haya sido el motivo fundamental por el que el legislador ha decidido reformar el concepto de consumidor más allá de lo que estaría obligado para trasponer la Directiva ${ }^{24}$

\section{El caso de las cooperativas de consumidores. ¿consumidor 0 empresario?}

Uno de los supuestos en los que cabría cuestionarse si el sujeto puede ser calificado como empresario a los efectos de sujeción a las

22 Así lo entiende Marín López, M. J.: ob. cit. p. 14.

23 Así lo considera, a nuestro juicio con acierto, CÁmARA LAPUenTE, S.: ob. cit. p. 101 refiriéndose al ejemplo de una asociación de vecinos que adquiere una motocicleta para sortearla y recaudar fondos y que, sin embargo, ve cómo la motocicleta padece faltas de conformidad. MARín LÓPEZ, M. J.: ob. cit. p. 15 concibe el ánimo de lucro no como la sola intención de obtener ganancias sino la intención de repartir esas ganancias entre los socios o miembros de la persona jurídica. Ello permitiría ensanchar el ámbito del concepto de consumidor al permitir la inclusión de entidades que, persiguiendo la obtención de dicha ganancia, no la destinan al reparto entre los socios sino a la consecución de los fines asociativos.

24 En este sentido se pronuncia Bercovitz Rodríguez-Cano, R. ob. cit. p. 64. Marín LOPEZ, M. J.: ob. cit. p. 15 saluda positivamente la referencia a estas entidades tan largamente reclamada por doctrina y jurisprudencia. 
normas de protección jurídica de los consumidores lo constituye el caso de las cooperativas de consumidores y usuarios. Incluso cabe plantearse, al igual que en el supuesto de fundaciones y asociaciones si, contrario sensu, podrían calificarse como consumidoras cuando intervienen en determinadas relaciones. Habría que distinguir en este punto dos planos: aquel en el que la cooperativa interviene como proveedora de bienes o servicios, considerando tanto las relaciones con sus socios como con terceros y un segundo plano en el que la cooperativa actúa no como proveedor de bienes o servicios sino como adquirente de los mismos.

\subsection{La cooperativa como proveedora de bienes o servicios}

Uno de los argumentos utilizados para negar la vinculación de la cooperativa por las normas de protección al consumidor es la ausencia de contraposición de intereses en las relaciones que la cooperativa mantiene con sus socios. Si el derecho de consumo surge como una herramienta para proteger a la parte débil en una relación contractual caracterizada por la existencia de intereses opuestos entre las partes, en el momento en que tal contraposición deje de producirse el propósito tuitivo quedaría sin justificación. Si la cooperativa se constituye, precisamente, para proporcionar a sus asociados las óptimas condiciones de acceso a los bienes y servicios que comercializa resultaría ciertamente difícil considerar que entre ellos existe el enfrentamiento posicional característico de las relaciones de consumo. Se dice que la cooperativa no es sino la suma de sus asociados y que por tal razón el acto de intercambio de bienes y servicios con sus socios no sería un acto de consumo en el sentido técnico del término no resultando, por ende, aplicable el derecho de consumo ${ }^{25}$.

En nuestra opinión, siendo apreciable este argumento, cabría realizar algunos matices importantes. Y es que el derecho de consumo surge sobre todo para atribuir al consumidor una serie de derechos y garantizarle su protección. Cierto es que, con carácter general casi unánime, la agresión de tales derechos se verifica en el seno de relaciones posicionalmente desequilibradas pero ello no significa que los escenarios de alteridad sean los únicos en los que se producen tales agresiones. La falta de alteridad no es en ningún caso un «antídoto» frente al abuso por parte

25 CRAcogna, D.: «La legislación de defensa del consumidor y las cooperativas», Boletín de la asociación internacional de derecho cooperativo, n. ${ }^{\circ} 45,2011$, p. 54-56. 
de la organización ${ }^{26}$. De forma tal que las cooperativas serán responsables frente a sus socios de los daños que la comercialización de sus bienes o servicios les puedan irrogar. De otra forma nos encontraríamos con que, siendo las cooperativas de consumidores un tipo societario consagrado a la protección de los mismos, se llegaría a la perversa situación en la que los socios de una cooperativa gozarían de un menor nivel de protección de sus derechos que el que les correspondería cuando contratan con otro empresario. Sería muy difícilmente sostenible que cuando un producto adquirido en una cooperativa padezca, por ejemplo, una falta de conformidad, la misma no va a generar ningún tipo de responsabilidad a la parte vendedora por ser la misma una cooperativa mientras que sí existiría tal responsabilidad en caso de haberse adquirido de un empresario persona física o de una sociedad. Por lo tanto, la cooperativa deberá cumplir con las normas de protección al consumidor aun cuando la relación de consumo se articule con sus socios.

Si clara resulta la vinculación de la cooperativa cuando contrata con sus socios, diáfana sería en el caso de comercialización de bienes y prestación de servicios a terceros no socios.

\subsection{La cooperativa como adquirente de bienes o servicios de otros empresarios}

Procede analizar ahora la otra perspectiva. Cuando la cooperativa adquiere bienes o servicios de otros empresarios para posteriormente emplearlos en su actividad cooperativizada ¿es merecedora de la protección que el ordenamiento reconoce al consumidor? Si por consumidor la LGDCU entiende aquel sujeto persona física o jurídica que actúa al margen de cualquier actividad empresarial o profesional cabría deducir fácilmente que la cooperativa no puede ser considerada como consumidora en tanto que cuando adquiere tales bienes lo hace con el propósito de revenderlos a sus socios o incluso a terceros lo que no es sino una genuina manifestación de una actividad empresaria|27. Cierto

26 En el ámbito societario y salvando todas las distancias con el caso que nos ocupa se reconocen mecanismos como la acción individual de responsabilidad mediante los cuales el socio de una sociedad pueda accionar contra la misma en el caso de que su actuación le haya irrogado cualquier tipo de perjuicio. Nos encontramos con un supuesto similar a la relación entre socio y cooperativa.

27 Procede traer a colación la ley 27/1999, de 16 de julio, de Cooperativas así como todas las normas autonómicas que califican las cooperativas de consumidores y usuarios como aquellas que «tienen por objeto el suministro de bienes y servicios adquiridos a terceros o producidos por sí mismas, para uso o consumo de los socios y de quienes con 
es que la cooperativa no tiene un ánimo de lucro asimilable al de las demás sociedades mercantiles pero desde el momento en que el ánimo de lucro no constituye un requisito tipificador de la condición de empresario su ausencia no tiene por qué suponer la calificación inversa.

Pese a todo ello sí que es cierto que en determinados ámbitos (suministros de telefonía, electricidad, acceso a internet, servicios bancarios y financieros y servicios aseguradores) de estructura oligopólica la posición de la cooperativa y en general de los pequeños empresarios frente a los proveedores de tales servicios dista mucho de ser una posición homogénea. La asimetría posicional de la cooperativa, que normalmente no tiene las dimensiones de los operadores en esos mercados, frente a las grandes corporaciones se aproxima a la que padece el consumidor en tanto que ambos carecen de cualquier fuerza negociadora. En este escenario la única norma comúnmente aplicable (aun cuando los consumidores pueden beneficiarse adicionalmente de las normas complementarias de la LGDCU) a consumidores y a los empresarios que padezcan esta situación de inferioridad es la normativa sobre condiciones generales de la contratación. En efecto, cualquier empresario puede beneficiarse de las medidas que la Ley 7/1998, de 13 de abril, sobre condiciones generales de su contratación contempla su aplicación tanto a las relaciones verticales trabadas entre un empresario (que actúa como predisponente del contrato) y un consumidor (adherente) como a las relaciones de carácter horizontal interempresarial proporcionando a todos ellos las mismas herramientas de defensa frente al empleo de condiciones generales de la contratación que, por vulnerar una norma imperativa o prohibitivia en perjuicio del adherente, puedan considerarse nulas ${ }^{28}$.

ellos conviven, así como la educación, formación y defensa de los derechos de sus socios en particular y de los consumidores y usuarios en general (...)».

28 El debate en torno a la posible extensión de la protección propia de los consumidores a los pequeños y medianos empresarios se suscitó durante la tramitación de la Directiva 93/13/CE, de 5 de abril de 1993, sobre cláusulas abusivas en los contratos celebrados con consumidores a raíz de un dictamen del Comité Económico y Social de la UE en el que se instaba a la Comisión "a que considere en un futuro muy próximo la posibilidad de prohibir las cláusulas abusivas en todos los contratos, independientemente de que estos se celebren o no con consumidores, teniendo particularmente en cuenta los problemas experimentados por las PYME» (DOCE C 159, de 17 de junio de 1991). También en el marco de la contratación mediante condiciones generales LETE ACHIRICA, J.: «La transposición de la directiva de 5 de abril de 1993 en el derecho francés: la ley de 1 de febrero de 1995, sobre cláusulas abusivas y presentación de los contratos», La Ley (Diario 3974), de 14 de febrero de 1996, pp. 1720-1728 se muestra igualmente partidario de una concepción extensiva del concepto de consumidor que incluya a los pequeños y medianos empresarios incluso cuando estos sean personas jurídicas. Hace re- 


\section{Bibliografía}

Bercovitz Rodríguez-Cano, A.: «El concepto de consumidor», en AzParren LuCAS, A. (dir): Hacia un código del consumidor, 2006, pp. 19-37.

Bercovitz Rodríguez-Cano, R.: "Comentario al artículo 3» en Bercovitz RodríGUEZ-CANO, R. (coord.): Comentario al texto refundido de la ley general para la defensa de los consumidores y otras normas complementarias, Cizur Menor, 2008.

Bercovitz Rodríguez-Cano, R.: «Comentario al artículo 3», en Bercovitz RodríGUEZ-CANo (dir.): Comentarios al Texto refundido de la Ley general para la defensa de los consumidores y usuarios y otras normas complementarias, 2. ${ }^{a}$ ed., Cizur Menor, 2015.

Calais Auloy, J.: Droit de la consommation, 9. ${ }^{a}$ ed, París, 2015.

CÁmARA LAPUENTE, S.: «El concepto legal de consumidor en el derecho privado europeo y en el derecho español: aspectos controvertidos o no resueltos», Cuadernos de derecho transnacional, marzo 2011, vol. 3, n. 1, pp. 84117.

ferencia el autor a la nutrida jurisprudencia francesa en tal sentido y particularmente a la sentencia del tribunal de casación de 28 de abril de 1987 en la que se dirime el conflicto entre una sociedad anónima dedicada al negocio inmobiliario y otra sociedad que le instala un sistema de alarma. El tribunal considera que el contrato celebrado «escapa a la competencia profesional» de la agencia inmobiliaria "cuya actividad de agente inmobiliario es extraña a la técnica muy especial de los sistema de alarma» y por esa razón "estaba en el mismo estado de ignorancia que cualquier otro consumidor». Se trata de la primera sentencia que considera consumidor a una persona jurídica permitiendo entender incluido en la noción amplia de consumidor a cualquier profesional que contrata fuera de su ámbito normal de actividad. En una línea similar se pronuncian la sentencia de la Corte de Casación de 25 de mayo de 1992 o la sentencia 24 de enero de 1995. En todos los casos se considera que cuando el empresario adquiere un bien o contrata un servicio que no está directamente relacionado con su tráfico empresarial padece idéntica situación de desprotección a la de un consumidor y por ello merece ser protegido de igual forma. Si bien no se trata de la línea jurisprudencial consolidada existen algunos pronunciamientos que van más allá y han considerado merecedores de especial protección incluso a empresarios que contrataban en el ámbito de su propia actividad profesional o empresarial. Así, la sentencia del Tribunal de Angers de 16 de diciembre de 1987 en la que se reconoce a un grupo de agricultores que sufrieron un corte de suministro eléctrico en sus explotaciones, la condición de consumidores frente a la compañía eléctrica alegando que "hayan utilizado la energía eléctrica para sus necesidades domésticas o para calentar sus invernaderos (...) en cuanto a la electricidad, se encontraban en el mismo estado de ignorancia que cualquier otro consumidor». El autor considera, sin embargo, que una ampliación excesiva de la noción de consumidor como la que propugnan los tribunales franceses puede convertirla en superflua por demasiado general. Se muestra partidario, en su lugar, de revisar la ratio de la protección y universalizar el control de las condiciones generales prescindiendo de la consideración subjetiva del adherente como finalmente han hecho las leyes nacionales en materia de control de condiciones generales de la contratación. 
CRACOGNA, D.: "La legislación de defensa del consumidor y las cooperativas», Boletín de la asociación internacional de derecho cooperativo, n. ${ }^{\circ} 45$, 2011, p. 54-56.

Lete AchiRICA, J.: «La transposición de la directiva de 5 de abril de 1993 en el derecho francés: la ley de 1 de febrero de 1995, sobre cláusulas abusivas y presentación de los contratos», La Ley (Diario 3974), de 14 de febrero de 1996, pp. 1720-1728.

MARín LÓPEZ, M. J.: «El nuevo concepto de consumidor y empresario tras la Ley 3/2014, de reforma del TRLGDCU», Revista CESCO de Derecho de consumo, n. ${ }^{\circ}$ 9, 2014, pp. 9-16.

MiRANDA SeRRANO, L.M.: "La protección de los consumidores en la contratación: aspectos generales», en Miranda SerRano, L.M.Nela Torres, P. J./PríES PICARDO, A.: La contratación mercantil. Disposiciones generales. Protección de los consumidores, Madrid, 2006, pp. 179 -221.

ReCalde CAstells, A.: «El derecho de consumo como derecho especial», en ToMILLo URBINA, J (dir.): El futuro de la protección jurídica de los consumidores, Navarra, 2008, pp. 537-568.

TOMILLO URBINA, J.: «Realidad y futuro del sistema arbitral de consumo: una aproximación crítica desde la experiencia cántabra», en TOMILLO URBINA, J. (dir.): Práctica arbitral de consumo, Cizur Menor, 2007, pp. 29-67.

VICENT CHULIÁ, F.: Introducción al Derecho Mercantil, Valencia, 2008. 